\title{
AS MOÇAS COM BRINCO DE PÉROLA: DIÁLOGOS ENTRE A LITERATURA, A PINTURA E O CINEMA
}

Juliana Rodrigues dos Santos - Mestranda em Estudos de Linguagens pela UFMS, Pós-Graduada em Produção Audiovisual: | Estéticas Contemporâneas pela UCDB, Graduada em Letras pela UFMS.

E-mail: cine_mais@ hotmail.com

Márcia Gomes Marques - Orientadora do trabalho. Doutora em Ciências Sociais pela Pontifícia Università Gregoriana, professora do Departamento de Comunicação Social, do Mestrado em Comunicação e do de Estudos de Linguagens, da Universidade Federal de Mato Grosso do Sul.

E-mail:marciagm@yahoo.com

\section{RESUMO}

Com o surgimento de diversas mídias e a consolidação dos meios eletrônicos de comunicação no mundo contemporâneo, as obras literárias migram com frequência para outras expressões artísticas como o audiovisual. A finalidade deste trabalho é refletir sobre o processo de recriação implicado na adaptação de uma obra fonte em outra. Para isso, selecionouse o quadro Moça com brinco de pérola do pintor Johannes Vermeer que serviu como fonte de inspiração para a feitura do livro também denominado Moça com brinco de pérola da escritora Tracy Chevalier e que posteriormente foi adaptado para o cinema pelo diretor Peter Webber com o mesmo nome. Questiona-se o critério de fidelidade como parâmetro de avaliação das obras adaptadas, deslocando o entendimento desse fenômeno para relação de hipertextualidade e tradução entre as obras escolhidas para análise.

\begin{abstract}
With the emergence of various media and consolidation of electronic means of communication in contemporary literary works often migrate to other artistic expressions such as audiovisual. The purpose of this paper is to discuss the rebuild process involved in the adaptation of a work in another source. For this, we selected the picture and Girl with a pearl earring painter Johannes Vermeer that served as inspiration for the making of the book also called Girl with the Pearl Earring author Tracy Chevalier and later was adapted for film by director Peter Webber with the same name. We question the criterion of faithfulness as a parameter for evaluation of works adapted, shifting the understanding of this phenomenon for hypertextuality relationship between translation and the works chosen for analysis.
\end{abstract}

Aculturar também é sinônimo de traduzir

Alfredo Bosi

\section{1) Introdução}

Quando o assunto em pauta envolve a transposição de obras literárias para o cinema, um dos questionamentos que vem à tona é se a obra adaptada se aproxima ou não da obra original. Essas produções, que estão sempre presentes na mídia, são alvos de constantes críticas, quando se julga a partir do grau de correspondência ao texto original.É importante frisar que a comparação entre as artes não é uma tendência da atualidade, pois, na poética de Horácio em18 a.C.,o paralelo entre as artes já 
existia;contudo, em torno do século XIX essa postura comparatista foi duramente criticada por se entender que cada arte possui suas especificidades, cada suporte, a sua linguagem.

Se não é coerente pensar a adaptação a partir do critério de fidelidade, como pensá-la então? Uma das molas propulsoras dos estudos de adaptação é a relação hipertextual existente entre as obras, ou estabelecer entre elas uma relação de tradução. Buscando analisar tais relações o artigo tem por objetivo discutir acerca das imbricações em transpor uma obra para outro formato. Quando há o descolamento do texto para outros suportes, há a necessidade de adequação do mesmo. A partir dessa proposta escolheu-se para estudo a pintura Moça com brinco de pérola (1666), do artista Johannes Vermeer, que foi fonte de inspiração para a escritora Tracy Chevalier compor a narrativa do livro também chamado de Moça com brinco de pérola (1999) e que posteriormente foi adaptado para o cinema por Peter Webber, em 2003, cujo título é homônimo às duas obras anteriores.

\section{2)Ut in cinematographicolitterarum est}

A literatura, por muito tempo, ocupou lugar de prestígio entre as artes. No entanto, com o advento das mídias eletrônicas, é notável que sejam essas mídias, como televisão, cinema, internet, a se destacarem atualmente. Pelo fato de se tratar de um meio de comunicação que propõe seus produtos em fluxo contínuo (Ellis,1999), as produções direcionadas a esse meio precisam ser abundantes, por esse motivo recorrem também à literatura com o objetivo de suprir a grande demanda de mercado.

Quando o cinema faz uso de textos literários para compor suas narrativas, é inevitável que haja a comparação entre as artes. O cerne da questão é desmistificar a relação de processo unidirecional existente entre literatura e película, cuja relação se dá a partir da idealização de uma arte maior e arte menor, sendo o audiovisual influenciado, portanto, menor, e a literatura influenciadora, por conseguinte, maior.

Quebrar com esse paradigma não é uma tarefa simplória, até porque a comparação entre as artes já era discutida na Antiguidade Clássica. Fica evidente uma comparação entre as artes na célebre expressão latina de Horácio Ut pictura poesis cujo significado refere-se ao paradigma pictórico no qual a linguagem poética (entende-se também por literatura) é concebida como imagem. Horácio destaca que um poema deveria ser como um quadro, ressaltando a similitude existente entre a poesia e a pintura. De acordo com a expressão Ut pictura poesis erit, que aparece na Epístola aos Pisões (2000), há o paralelo entre a poesia e a pintura, fazendo desta última o ponto referencial de comparação. Como está posta na poética de Horácio, a expressão gera 
uma primazia em favor das artes da imagem, com as quais são relacionadas às artes da linguagem.

Ao recuperar a expressão da Epistola aos Pisões, os teóricos do Renascimento alteraram a ordem do termo: Ut pictura poesis erit transformou-se em Ut poesis pictura, cujo significado passou a determinar que a pintura é como a poesia, o quadro como o poema, privilegiando a escrita ao invés da imagem; e foi tal inversão de sentido que a tradição preservou. Até a segunda metade do século XVIII, o princípio Ut poesis pictura foi amplamente aceito.Nesse contexto, a arte da literatura era considerada uma arte maior se comparada às outras artes.

É importante frisar que nem sempre os escritores, pintores e teóricos foram defensores da proximidade entre as artes, por isso, a doutrina de Ut pictura poesis foi contestada no texto Laocoonte, de Gotthold Ephraim Lessing, uma das figuras de maior destaque do panorama intelectual do século XVIII: esteta, dramaturgo, teórico e crítico literário. Publicado em 1766, o Laocoonte, de G. E. Lessing, é considerado uma das mais notáveis reflexões acerca das semelhanças e diferenças entre a poesia e a pintura. Sua influência sobre o pensamento estético alemão e europeu foi enorme. O autor de Laocoonte ressalta que tal comparação tende a considerar a poesia como original, e a arte da pintura como copista. No entanto, é fundamental destacar que:

Se o Laocoontede Lessing constitui uma data fundamental na história do Ut pictura poesis, não assinala seu fim. Violentamente criticada ao longo do século XIX pelos defensores da modernidade, essa doutrina renasceria várias vezes de suas cinzas e sua história prosseguiria no século XX, de uma forma mais ou menos latente. (Lichtenstein, 2005, p. 11)

De acordo com Claus Clüver:

A velha metáfora da "irmandade das artes" é uma tentativa de camuflar uma incompatibilidade e uma velha rivalidade: pictura não é ut poesis, e chamar uma pintura de "poema silencioso" ou descrever um poema como "pintura que fala" não é uma enunciação retoricamente elegante, mas uma afirmação de superioridade da poesia. (1997, p.43)

E é nesse contexto de superioridade da arte da linguagem que nasce a arte do cinema, já tendo que se empenhar para conquistar o seu espaço como arte. O cinema não escaparia à doutrina do Ut pictura poesis, ou melhor, reconfigurando os termos, $u t$ in cinematographico litterarum est:como a literatura, deve ser o cinema e a acusação de arte copista não tardaria a vir.Estar no status de copista não garante autonomia, além de receber a culpabilidade de se valer das ideias alheias para se firmar como arte. Isto também porque 
Quando porventura se confere a uma arte o papel dominante, este se torna o protótipo de toda arte: as outras tentam se despojar de suas próprias características e imitar-lhe os efeitos. A arte dominante, por sua vez tenta ela própria absorver as funções das demais. Disso resulta uma confusão das artes, pela qual as subservientes são pervertidas e distorcidas; são obrigadas a negar sua própria natureza no esforço por alcançar os efeitos da arte dominante. (Greenberg, 2001, p.46)

Essa assertiva ainda possui um peso considerável em se tratando de obras adaptadas para o audiovisual. Quem vai assistir a uma releitura advinda da literatura espera muitas vezes encontrar na íntegra o livro no audiovisual. Esse espectador/leitor idealiza ser possível que uma história narrada no livro seja rigorosamente adaptada para o audiovisual.

\section{3) Como pensar a adaptação hoje?}

Como deve ser a análise de uma adaptação que não seja pelo crivo da fidelidade? Ainda que pautados nas obras literárias, os diretores imprimem, na película, suas crenças, seus objetivos e sua estilística. Assim, eles buscam ou aproximar, ou equivaler, ou dialogar, ou corresponder, ou traduzir o texto literário ao cinematográfico, observando as possibilidades de imbricação de um meio com o outro, tendo em vista aquilo que desejam expressar.

Seguir o texto-fonte página por página não deve ser o objetivo do cineasta, pois não é interessante para a narrativa propor um livro na íntegra projetado na película sem modificações. Bazin argumenta que os textos literários não devem ser vistos como sinopses dos filmes, já que, para ele, “seguir o livro página por página é algo diferente e outros valores estão em jogo e que o objetivo do cineasta não deve ser o de transcrever para a tela uma obra cuja transcendência ele reconhece a priori." (1999,p. 82-83).Por isso, pensar a adaptação como tradução é uma das molas propulsoras dos estudos de adaptação.Traduzir é propor modificações, cortes e adequações. Traduzir é interpretar. Mesmo uma tradução interlingual não consegue ser exata ao texto-fonte. Para Walter Benjamim,

nenhuma tradução será viável se aspirar essencialmente a ser uma reprodução parecida ou semelhante ao original. Isso porque o original se modifica necessariamente na sua "sobrevivência", nome que seria impróprio se não indicasse a metamorfose e renovação de algo com vida. (2008, p. 30)

Benjamin defende que toda tradução precisa encontrar na língua em que se está traduzindo a intenção por onde o eco do original possa ser ressuscitado; caso isso não 
ocorra, a tradução não é bem sucedida. O tradutor deve se preocupar em transmitir a "intenção" do texto-fonte e esse processo só se torna eficaz a partir do momento em que ocorrem metamorfoses no texto. Uma tradução traz, portanto, em seu corpus, modificação; logo, uma tradução literal se torna inviável, porque o texto traduzido carrega consigo as marcas de outros textos.

O processo de transposição se dá a partir da procura de equivalências entre os códigos. Isto quer dizer que um elemento y que ocupa um lugar específico num determinado sistema de signos, o teatro, ou livro seria substituído, na tradução, por outro elemento $y^{\prime}$ que pudesse preencher a mesma função, contudo em outro sistema de signos.

O cerne da ideia de equivalência provém, então, do fato de que toda linguagem possui um regulamento básico; logo, entende-seque os signos não se amontoam, e sim se estabelecem em sistemas semânticos e sintáticos organizados e coesos. Este é o nível da tradução intersemiótica. Assim, a equivalência não se revela através da igualdade que não pode ser encontrada nem dentro da mesma língua, mas como processo. A equivalência se dá na dialética entre os códigos dos textos de partida e o texto de chegada.

A tradução intersemiótica implica que, ao decodificar ideias propostas em uma linguagem e codificá-las por intermédio de um sistema semiótico distinto, tem-se a necessidade de transformá-las, porque todo sistema semiótico é caracterizado por qualidades e restrições próprias, e nenhum conteúdo existe livremente do meio que o incorpora. Não há possibilidade de esse conteúdo ser transmitido, ou traduzido, de maneira independente de seu sistema semiótico. Segundo Plaza,

A transposição de um signo estético num meio determinado para outro meio tecnológico deve obedecer os recursos normativos (signos de lei) do novo suporte, seus sistemas de notação. Não parece ser outra coisa que Gombrich pretendeu expressar quando afirma: "O artista não pode traduzir mais do que seu meio pode traduzir". Assim, todo suporte declara e impõe suas leis que conformam a mensagem. (2003, p. 109)

A reunião dos sistemas de signos cinematográficos pode ser considerada como um construto ao qual damos um significado. O mesmo acontece com o conjunto de signos teatrais, poéticos, imagéticos. Juntos, constroem o conjunto no qual se integram o que denominamos, neste processo de laboração, de aspectos intersemióticos da tradução. Contudo, em adaptações de obras para outro meio, pode-se pensar também em uma relação hipertextual. Segundo Diniz, 
O que a hipertextualidade enfatiza não são as similitudes entre os textos, mas as operações transformadoras realizadas no hipotexto. Algumas delas desvalorizam e trivializam os textos pré-existentes, outros reescrevem-nos em outro estilo; outros reelaboram certos hipotextos cuja produção é, ao mesmo tempo, admirada e menosprezada. (2005, p.44)

Nessa ótica, não há, portanto, um texto considerado original, já que aquele que se denomina inventado é, de certo modo, a junção de outros textos já existentes. Propor a adaptação como uma relação de hipertextualidade é compreender que há a fusão e incorporação de um texto em outro, sendo que nenhum deles é propriamente original.

\section{4) Desmistificando o mito}

Não é de hoje que há esforços para desmistificar a comparação servil entre as artes, em que uma arte é priorizada em detrimento da outra. Cada arte possui sua especificidade e, já no século XIX, Charles Baudelaire descreve que a "necessidade de encontrar a qualquer preço pontos de comparação e analogia entre as diferentes artes, leva, muitas vezes, a estranhos equívocos, o que prova como as pessoas entendem pouco do assunto." (Lichtenstein, 2005, p.104)

Em sua exposição, Baudelaire explicita que cada arte deve usar sua linguagem própria para compor suas obras artísticas. De acordo com o poeta, cada arte deve sugerir os sentimentos que deseja a partir de seus códigos. Embora o poeta esteja se referindo à poesia e à pintura, tal premissa é válida para os estudos de adaptação de obras literárias.

A partir do momento em que se discute a respeito de adaptação de textos literários, deve-se ressaltar que os códigos que regem o cinema e a literatura são diferentes. Enquanto o primeiro trabalha com imagens, o segundo explora o código verbal. Por isso, adaptar um texto literário é um processo complexo, pois ler um livro e assistir a um filme são experiências bem distintas. (Hutcheon, 2007)

São poucas as vezes que efetuamos a leitura de uma obra literária em um único momento. Ao ler, temos mais tempo à nossa disposição, lemos nos momentos que dispusermos parar isso e determinamos o ritmo da leitura; fato esse que não acontece com o audiovisual, pois tal ritmo já vem pré-determinado. O romance pode ser lido por capítulos, por etapas, já a linguagem do audiovisual, de acordo com Rey, "não oferece essas vantagens. Tem de prender o espectador logo de começo e desenvolver em 100 minutos uma história que ele leria em dez ou muito mais horas" (1997, p.60)

Além disso, um dos pontos fundamentais que diferencia as duas linguagens e que deve receber atenção na adaptação é a dinâmica do tempo. Vários romances e livros 
são escritos no passado. É constante o uso de expressões como "ele pensou”, “ela foi”, "ele disse", demarcando, portanto, um tempo que não é presente.

Segundo Seger, "na maioria dos casos, o narrador está voltado a eventos passados que nos são contados e interpretados por ele". (2007, p. 40) Outras vezes o tempo na literatura é fluido, desloca-se para frente e para trás, variando entre o passado, presente e futuro. Por exemplo, um personagem que se encontra no presente pode nos dar informações importantes sobre o passado através da narração do que já passou. Já a o audiovisual, seja filme ou televisão, explora mais o tempo presente, porque filmes que usufruem em abundância de flashbacks são, por muitas vezes, cansativos. Seger ressalta que os filmes

\begin{abstract}
Estão mais interessados no que vai acontecer do que naquilo que já aconteceu. Em alguns filmes, esses movimentos em direção ao futuro é mais lento e gradativo. Em outros, o espectador sente-se quase que lançado para frente, em direção a um clímax importante e inevitável (2007, p. 42)
\end{abstract}

Nas narrativas fílmicas o tempo presente prevalece pelo fato de que o filme é imediato. Ainda sobre esse assunto Balogh afirma, em análise feita da adaptação de Vidas Secas, que "o critério organizador do filme é o espaço e a temporalização básica, o presente. As referências ao futuro são quase sempre verbais". (2004, p. 135) Além disso, é preciso se preocupar também com a construção dos detalhes no espaço fílmico.

Embora tanto a literatura quanto o cinema se utilizem de ações para contar suas histórias, nota-se, muitas vezes, que um livro precisa de oito ou nove páginas para comunicar uma ação que no audiovisual demoraria em torno de três minutos. Logo, a linguagem audiovisual constrói minúcias através da imagem. "A câmera pode focalizar um objeto tridimensional e, em questões de segundos comunicar detalhes que ocupariam páginas e páginas de descrição em um livro" (Seger, 2007, p. 34). Devido a essa dinamicidade das imagens, as emoções afloradas no leitor/espectador também são diferentes. Segundo Aguiar,

Na literatura, os estímulos emotivos vêm após os leitores atravessarem uma verdadeira cortina de operações semânticas e sintáticas guiadas por signos, materializados em palavras e organizados em conceitos. Já no cinema (em certa medida poderíamos ampliar a ideia para TV), a presença da imagem visual desperta reações imediatas, incluindo-se as fisiológicas, com risos, lágrimas, descargas de adrenalina e outros (2003, p.120)

Xavier, em seu livro A experiência do cinema, enfatiza que a imagem é um signo que mais se aproxima da realidade que representa, por isso, a reação imediata; já 
as palavras são consideradas símbolos indiretos, que são construídos por intermédio da razão, por conta disso são muito distantes do objeto. Para sensibilizar o leitor, a palavra tem a necessidade de passar novamente pelo circuito dessa razão que a produziu, de forma que essa precisa ser decodificada antes de desencadear a representação da realidade, e, por conseguinte, evocar os sentimentos do leitor. "A imagem animada, ao contrário, forma por ela própria uma representação já semipronta que se dirige à emotividade do espectador quase sem precisar da mediação do raciocínio." (1983, p. 293).

Ao ler um livro,vê-se aquilo que o narrador quer nos revelar em particular. Se naquele momento o narrador enfatiza uma determinada ação, o leitor também deve colocar sua atenção nessa ação. Se o narrador aborda assuntos referentes a sentimentos, é preciso que o leitor se concentre nesses sentimentos também. Na narrativa literária tem-se um processo de cada vez, temos que acompanhar as ações de maneira sucessiva.

No que diz respeito à linguagem do audiovisual, essa tem muitas dimensões, haja vista que em uma única cena, desde que seja bem elaborada, pode-se mostrar personagens, levar a ação adiante, construir uma imagem, tudo ao mesmo tempo. "No filme, as sequências, mesmo se lembradas, articulam-se muito mais evidentemente como uma sucessão de presentes: isto+isto+isto+isto...”. (Aguiar, 2003, p.122)

Já o audiovisual televisivo, embora abarque as diferenciações até aqui expostas, possui singularidades se comparado à linguagem cinematográfica. Tais distinções devem ser levadas em consideração no momento da adaptação de textos literários. A programação televisiva é disponibilizada para o telespectador o dia inteiro, por isso é necessário que haja uma gama de conteúdo considerável para alimentar esse meio. Para sustentar tamanho consumo, a televisão gera seus programas de forma industrial e enfatiza a criação em série; por isso, a televisão tem uma linguagem repleta de "fragmentação que demanda um número de interrupções no fluxo de cada programa para dar lugar aos tão decantados intervalos para comerciais". (Balogh, 2004, p.144) Quem adapta obras literárias para a televisão precisa se preocupar em elaborar uma narrativa que permita cortes, de forma que essas suspensões despertem o interesse do público para assistir a novela ou minissérie no dia seguinte.

Quem deseja adaptar uma obra literária para o cinema ou televisão deve propor soluções e traduções criativas de acordo com o seu suporte. $\mathrm{O}$ adaptador deve contribuir para que a história, no audiovisual, seja contada de maneira adequada a permitir que a narrativa flua com clareza e leveza e que possua uma coerência interna como teria a narrativa no romance. Esse deve ser o esforço dos adaptadores: propor uma narrativa coesa.

\section{5) Diálogo hipertextual entre a pintura e a literatura}


Um dos quadros mais famosos do pintor Johannes Vermeer serviu de suporte para a escritora Tracy Chevalier desenvolver a narrativa do livro Moça com brinco de pérola (2002), mesmo título do quadro de Vermeer. A narrativa retrata a história fictícia de como o artista teria feito essa pintura. A figura 1mostra o quadro que serviu como ponto de partida para o livro da escritora.

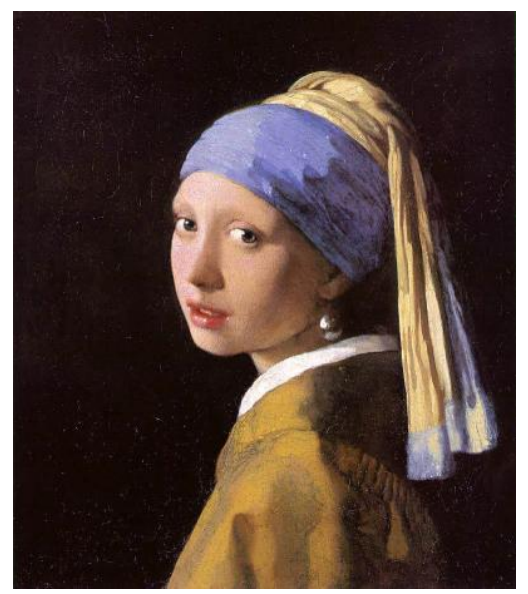

Figura 1 - Moça com brinco de pérola de Vermeer Fonte: http://aidobonsai.galeria-de-johannes-vermmer

A moça com brinco de pérola recebe o nome de Griet no livro uma camponesa, cujo pai é um ex-pintor de cerâmica que perdeu a visão devido a um acidente de trabalho. Por conta das péssimas condições financeiras da família, a moça é forçada a deixar sua casa para trabalhar como criada para a família do pintor Johannes Vermeer.

Ele vive com a esposa, que é muito possessiva e ciumenta, e os filhos. Ao limpar o ateliê do pintor, Griet começa a observar as obras de seu patrão. O pintor nota seu interesse pelos quadros e ao longo da narrativa coloca a criada como auxiliar, já que ela aprende com facilidade o que o patrão lhe transmite sobre combinação de cores na arte. O interesse pelas criações do pintor é tão elevado que Griet acaba se tornando parte vital de sua obra. Na proporção em que a intimidade dos dois aumenta, cresce também a tensão e a desilusão de uma casa que antes era calma e cheia de ordem.

A autora se ancorou na biografia do pintor Vermeer, como o lugar em que nasceu, cidade do Delft, localizada na Holanda, quantos filhos teve, com quem se casou, situação econômica, a fim decompor uma narrativa de cunho fictício. Além disso, há citações e alusões feitas às obras do pintor que já são identificadas através da própria capa do livro, figura 2. 


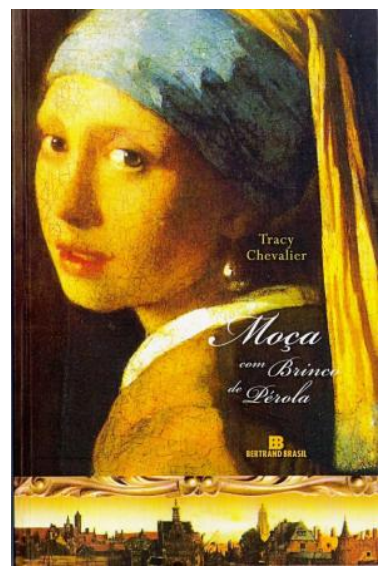

Figura 2 - Capa do livro de Chevalier (2002)

Fonte: http://rosangelaneres.com

Nota-se, portanto, uma relação de hipertextualidade entre quadro e livro, já que se entende que hipertextualidade é qualquer relação estabelecida entre um texto A e um texto B. Na parte inferior da capa do livro há uma pintura da cidade de Delft. Lá Johannes Vermeer nasceu e morreu. Na figura $3{ }^{1}$ há outro quadro do pintor holandês representando a cidade de Delft que é a mesma imagem da capa do livro de Chevalier.

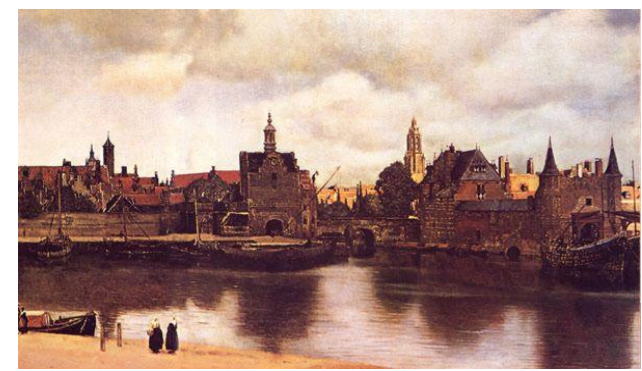

Figura 3: Vista de Delft de Johannes Vermeer (1661)

O contexto histórico é bastante evidenciado em Moça com brinco de pérola de Chevalier. Na trama há a presença marcante de Pieter Claesz van Ruijven, que teria sido patrocinador de Vermeer. Ele comprava muitos de seus quadros. No livro, além de assumir esse papel, também foi responsável por pedir a pintura da criada que lhe chamara a atenção - Griet- por quem teria se afeiçoado e desejado ao longo da história.

Outra personagem que auxilia na composição da narrativa no livro é Antonie van Leeuwenhoek, amigo da família. Ele teria dado a Vermeer uma caixa que recebeu o nome de câmera escura. A caixa é um tipo de aparelho óptico que registra a imagem, o qual deu base para a invenção da fotografia. Sugere-se, no livro, que a câmera escura teria contribuído para que o artista pudesse registrar as ações cotidianas e pintá-las. Embora não haja, de fato, nenhuma informação documental que comprove que o pintor 
usou o equipamento, há especulações por conta das informações visuais exibidas pela sua própria pintura quanto a discrepâncias na escala das figuras. É importante frisar que Antonievan Leeuwenhoekera contemporâneo do artista, era cientista e fez importantes contribuições para melhorar o microscópio.

Fatos históricos se fundem com narrativas ficcionais no livro, gerando um forte diálogo hipertextual. São essas reelaborações e referências à história que podem ser encontradas nos escritos de Tracy Chevalier.

\section{6) Diálogo de tradução entre a literatura e o cinema}

O livro virou filme. Moça com brinco de pérola de Chevalier foi adaptado para o cinema pelo diretor Peter Webber. A história segue a mesma linha narrativa da do livro, sem perder o diálogo com as obras do pintor barroco. Griet recebe um rosto, que é o da atriz Scarlett Johansson. Dar um rosto/corpo à personagem não é uma tarefa simplória em um processo de adaptação, ainda mais quando um rosto já está dado por uma pintura. A representação visual de Griet não ignorou o quadro de Vermeer, nota-se que o diretor optou pela similitude das imagens, embora não precisasse, já que o filme, em primeiro lugar, deve preservar sua autonomia enquanto obra, pois não estamos mais lidando com uma tradução servil. Nesse caso, traduziu-se para o audiovisual o que foi descrito no livro sobre a personagem ao qual se somou a imagem já pré-estabelecida do pintor holandês. Foram estabelecidas equivalências, como propõe um processo de tradução. Na figura 5 visualiza-se o cartaz do filme.

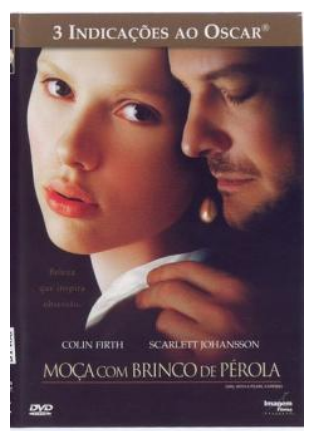

Figura 5 - Capa do DVD de Peter Webber (2003)

Fonte: http://suzannearte.blogspot.com.br

Por conta do apelo comercial, nota-se a presença da personagem de Vermeer no cartaz, interpretado pelo ator Colin Firth. Já a imagem que segue abaixo, figura $6^{2}$, indica o empenho em transpor para o audiovisual a famosa tela do artista. 


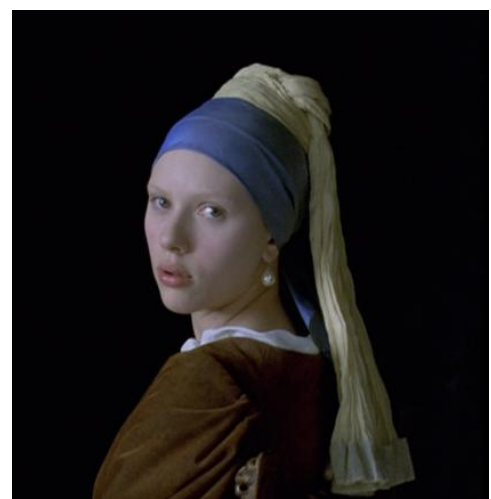

Figura 6 - A criada Griet no filme de Webber

Preocupado em traduzir a "intenção" dos textos-fontes, tanto de Chevalier quanto de Vermeer, o diretor se apoiou na narrativa literária para produzir a sua história, e nas pinturas para elaborar o cenário do filme. A equivalência entre o ambiente das pinturas e o cenário do filme é acentuada. Longe de ser uma tradução servil, já que essa é inviável num processo de transposição, o cenário no filme de Peter Webber procura traduzir a ambientação expressa no livro através dos retratos de Vermeer. As figuras que seguem, 7, 8 e 9, são cenas contidas no filme que foram compostas a partir do quadro Mulher com colar de pérolas (1664).

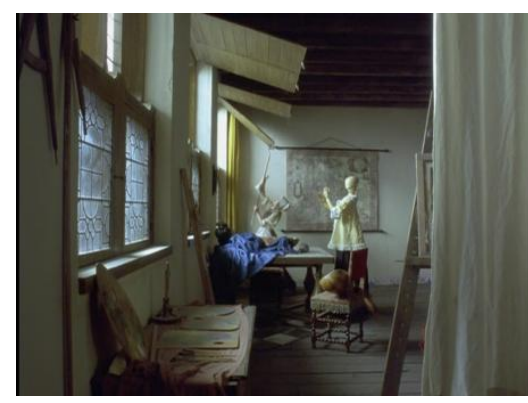

Figura 7 - Griet limpa o Ateliê

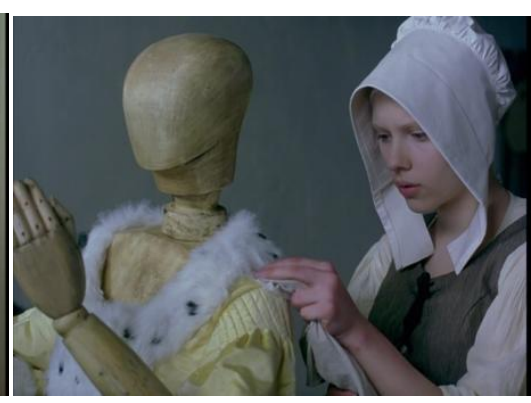

Figura 8 - Griet limpa o casaco

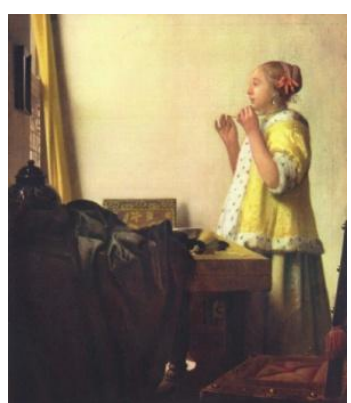

Figura 9 - Mulher com colar de pérola (1664) 
Também é notável a semelhança entre o ambiente do filme e o espaço da pintura nas figuras 10 e 11. Do lado esquerdo, figura10, o pintor, no filme, vê Griet limpando as janelas e a partir daí idealiza o quadro Moça com pichel de água, quadro esse feito pelo pintor entre 1662 e 1663, conforme representado na figura 11.

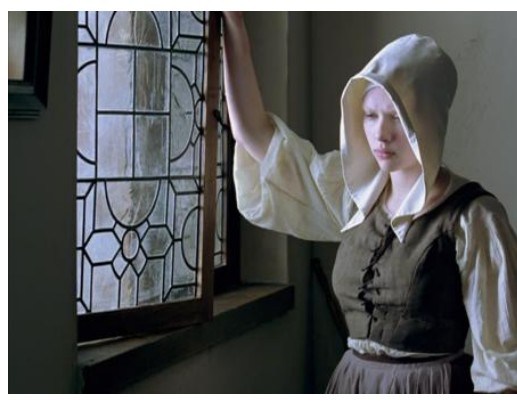

Figura 10 - Griet na janela

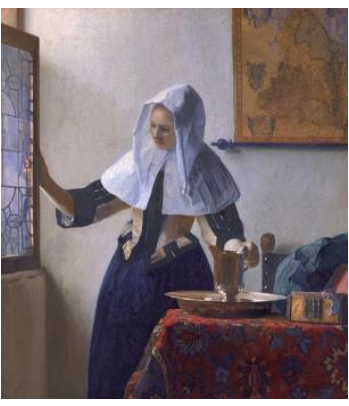

Figura 11 - Moça com pichel de água

Na figura 12, a criada observa o patrão pintando o quadro. Na história contada por Chevalier, o acesso ao ateliê de Vermeer era restrito e o diretor Peter Webber optou por manter a mesma linha narrativa, apenas Griet e a sogra do pintor eram autorizadas a entrar no espaço de trabalho do artista. Esta última porque era ela a responsável por negociar os quadros.

Segundo a narrativa fílmica Griet contribuía com sugestões significativas para a organização visual dos quadros do pintor. Na figura 12 há a presença de uma cadeira junto à mesa no lado direito da cena; cadeira essa que foi retirada pela criada, embora houvesse uma ordem expressa de que era para limpar o ateliê sem tirar nada do lugar. $\mathrm{O}$ pintor teria gostado dessa nova organização visual e retirado do quadro a cadeira.

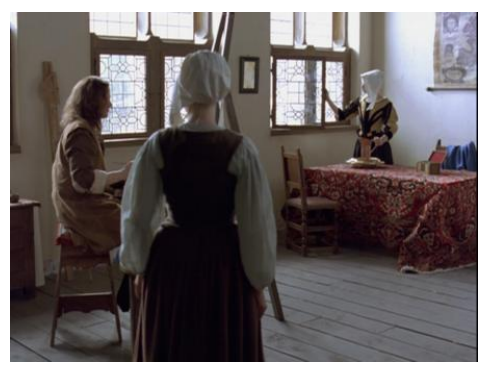

Figura 12 - Griet observa o pintor.

Há um intenso diálogo também entre a figura 13 e 15, que foram extraídas do filme, e outro quadro do pintor intitulado $O$ concerto (1666). A senhora da figura 15, que é esposa do pintor no audiovisual, se assemelha com a mulher da figura 14. Nota-se que o figurino dessa cena do filme, assim com outras, é construído a partir das pinturas 
de Vermeer. O chão em preto e branco, frequente nos quadros de Vermeer, aparece em demasia no ambiente fílmico.

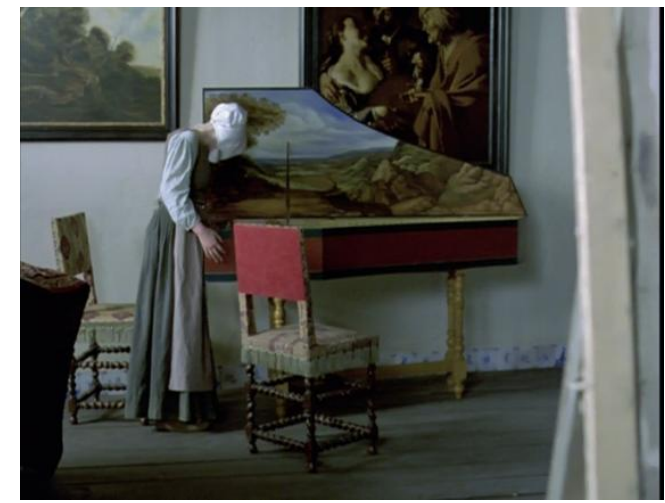

Figura 13- A criada e o piano

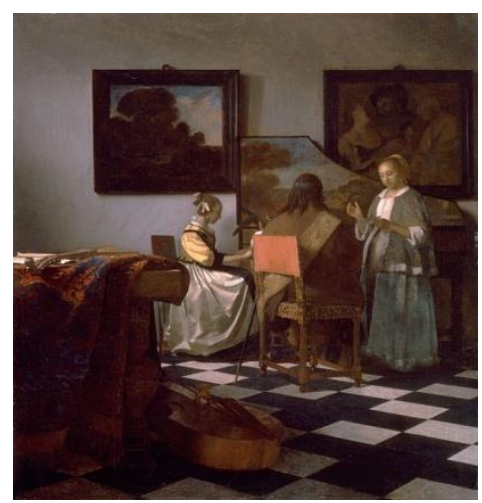

Figura 14 - O concerto (1666)

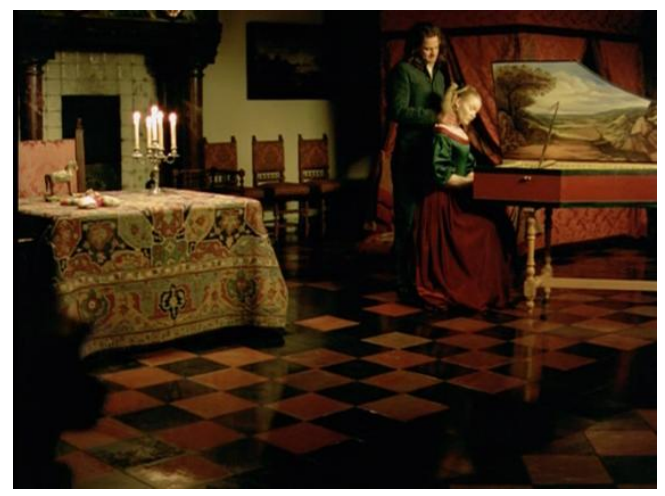

Figura 15 - Catharina tocando piano

O diretor Webber faz uma adaptação criativa das obras vistas e lida, que consiste na "tradução de elementos como esses - sensações, sentimentos e pensamentos dos personagens, incluindo a atmosfera ou o humor de toda uma situação-o que caracteriza o processo de 'adaptation proper' ou adaptação criativa.” (Diniz, 2005, p. 22) É evidente, no entanto, que a adaptação criativa requer transformações e modificações. Transpor uma obra literária na íntegra para outro formato como o audiovisual sem modificações, como já foi sublinhado, não é ideal. O texto da escritora Tracy Chevalier passa por modelações para chegar ao cinema. É perceptível a mudança desde o começo quando o primeiro capítulo é suprimido no audiovisual. Assim se segue o início da narrativa no livro:

Minha mãe não me contou que eles estavam vindo. Depois, disse que não queria que eu parecesse nervosa. Fiquei surpresa, porque achava que ela me conhecia bem. Estranhos 
poderiam pensar que eu estava calma. Não chorei como um bebê. Só minha mãe notaria meu maxilar duro, meus olhos grandes e arregalados. Cortava legumes na cozinha quando ouvi na porta da frente de nossa casa: uma voz feminina, radiante como latão polido, e de um homem, grave e sombrio como a madeira da mesa onde eu estava trabalhando. (Chevalier, 2002, p.09)

Quem entra na casa de Griet é o pintor Vermeer e sua esposa e é nessa parte que o artista nota que a futura criada corta os legumes e separa-os por cores, esse modo diferente de organizar o alimento chama a atenção do pintor. Esse é um dos motivos que fará com que o pintor tenha outro olhar para a empregada. Ao ser indagada a respeito de seu trabalho, o artista recebe a seguinte resposta:

Vejo que separou os brancos - disse ele, indicando os nabos e cebolas. - Depois, o laranja e o roxo não estão juntos: por quê? Pegou uma tira de repolho e uma rodela de cenoura e misturou-os como dados na mão [...] - As cores brigam quando ficam lado a lado, senhor. (Chevalier, 2002, p.11)

Essa primeira parte do livro é cortada no audiovisual, ao assistir o filme o espectador tem ciência, apenas, de que a família está passando por um momento de crise financeira e que Griet teria que trabalhar para prover a família, já que seu pai, agora cego por conta de um acidente não poderia mais fazer o que fazia antes, que era pintar azulejos. Cortes de capítulos e acelerações na narrativa são algumas das transformações feitas para que fosse viável transpor livro para o cinema

Uma das alterações mais significativas ao transpor a obra para a película referese à postura de algumas personagens. A criada Griet não interfere tanto na feitura das obras do pintor, ela é mais obediente; a criada Tanneke, que no livro era responsável por causar confusão entre Griet e a família, é mais receptiva à nova criada no filme. $\mathrm{O}$ namorado de Griet, no filme, incorpora bem a imagem de bom moço, distinta da imagem que é transmitida no livro, pois Pieter é um homem que está disposto a casar com a criada a qualquer forma, por isso faz questão de lembrá-la da péssima condição financeira de seus pais e que é ele quem fornece a carne para a família.

Além disso, no audiovisual, O pintor Vermeer revela-se mais defensor de Griet do que no livro. Se nos escritos sua postura é neutra perante a família, no audiovisual a preferência se torna evidente. Os pais e irmãos de Griet aparecem pouco no filme, pois quase todas as partes são extraídas da narrativa fílmica, nem mesmo a morte da irmã de Griet aparece no filme e sua constante preocupação com a família é substituída pela sua intensa relação com seu patrão. Tais mudanças são compreensíveis se levarmos em consideração o público alvo do livro e o público alvo do cinema, por exemplo. São mudanças que fazem parte de um processo adaptativo criativo. 


\section{7) Considerações finais}

Ao propor uma análise que envolve transposições interartes é preciso que todos os elementos sejam considerados no momento da avaliação, como as intenções que existem por detrás de cada adaptação. $\mathrm{O}$ ato de passar o texto para outro suporte é um processo de fluxo contínuo, de maneira que se usa o passado para atualizar o texto no novo suporte. O filme Moça com Brinco de pérola fez isso, pois o diretor usou como referência para desenvolver a narrativa na película tanto as obras do pintor holandês quanto o livro de Chevalier. Assim foi possível dialogar, recuperar a estética de Johannes Vermeer. Embora tenha usado o livro, o foco principal era as obras de Vermeer.

Enquanto Chevalier usou a história do pintor Vermeer para escrever a narrativa do livro aliando fatos reais a situações imaginárias, o diretor Webber fez uso de duas fontes, o livro de Chevalier e os quadros de Vermeer para compor a narrativa cinematográfica. Como é ideal para uma tradução, houve supressões de capítulos, modificações na postura das personagens a fim de tornar a narrativa coesa, pois toda tradução requer transformação.

As reflexões aqui estabelecidas a respeito da migração de obras artísticas para outros suportes apontam para o caminho de que não é possível uma correspondência integral entre as artes. Todas as vezes que há transposição de obras literárias para outro formato é preciso que haja modificações, a fim de que a adaptação seja bem sucedida. Por isso, propõe-se outra relação que não seja pelo critério de igualdade entre as artes. Uma das propostas é pensar a adaptação como tradução do texto-fonte. Traduzir significa procurar equivalência, pois dentro do processo de tradução é possível encontrar um elemento que desempenhe a mesma função em outro sistema de signos diferente, respeitando as limitações e peculiaridades de cada suporte.

\footnotetext{
${ }^{1}$ Fonte das figuras 3, 9, 11, 14: http://pt.wikipedia.org/wiki/Johannes_Vermeer

${ }^{2}$ Fonte das figuras 6, 7, 8,10, 12, 13, 15: DVD Moça com brinco de pérola do diretor Peter Webber (2003).
} 


\section{REFERÊNCIAS}

AGUIAR, Flávio. Literatura, Cinema e Televisão. São Paulo: Editora Senac. São Paulo Itaú cultural, 2003.

BAZIN, Andre.O cinema. Trad. Heloisa de Araújo Ribeiro. São Paulo: Brasiliense, 1999.

BALOGH, Anna Maria. Conjunções - Disjunções - Transmutação:da literatura ao cinema e à TV. São Paulo: Annablume, 2004.

CHEVAlIER, Tracy. Moça com brinco de pérola. Trad. Beatriz Horta. Rio de Janeiro: Editora Bertrand Brasil, 2002.

CLÜVER, Claus. Estudos Interartes. Conceitos, termos, objetivos. In: Literatura e sociedade, Revista de Teoria literária e Literatura Comparada, $\mathrm{n}^{\circ}$ 2, FFLCH, 1997, USP/São Paulo, p. 37-55.

ELLIS, J. Broadcats TV as cultural form.IN: T. BENNETT (ed.) POPULAR FICTION. London, 1999. p. 33-45.

DINIZ, Thaïs Flores Nogueira. Literatura e Cinema: tradução, hipertextualidade e reciclagem. Belo Horizonte: Editora UFMG, 2005.

GREENBERG, Clemente. Rumo ao novo Laocoonte. In: FERREIRA, Glória e COTRIN, Cecília (orgs.) Clemente Greenberg e o debate crítico. Rio de Janeiro: Jorge Zahar, 2001, p. 45-60

HORÁCIO. Arte poética ou Epístola aos Pisões; São Paulo: Cutrix, 2000.

LESSING, Gotfried. Laocoonte. In: LICHTENSTEIN, Jacqueline. Op. Cit. São Paulo, 2005, p.82-92.

LICHTENSTEIN, Jacqueline. A pintura. Textos essenciais. Vol. 7, São Paulo, O paralelo entre as artes. Ed. 34, 2005.

PLAZA, Júlio. Tradução Intersemiótica. São Paulo: Perspectiva, 2003.

REY, Marcos. O Roteirista profissional: televisão e cinema. São Paulo: Editora Ática, 1997.

XAVIER, Ismail. A experiência do Cinema. Rio de Janeiro: Editora Graal, 1983. 
FILMOGRAFIA

WEBBER, Peter. Moça com brinco de pérola. Imagem filmes, 2003. DVD, 99 min. 